\title{
SIMBOLISASI PADA RANCANGAN ARSITEKTUR GEREJA KATOLIK SANTO PETRUS DAN GEREJA KATOLIK SANTA PERAWAN MARIA TUJUH KEDUKAAN DI KOTA BANDUNG
}

\author{
Meielisa Chrisylla \\ Magister Arsitektur, Program Pascasarjana, Universitas Katolik Parahyangan, Bandung, Indonesia \\ Email: meielisach@gmail.com
}

\begin{abstract}
Abstrak
Gereja Katolik sebagai tempat peribadatan harus memiliki ekspresi sakral baik secara eksterior maupun interior. Diduga modernisasi menyebabkan pudarnya ekspresi sakral pada Gereja Katolik.

Mengingat Gereja katolik adalah bangunan ibadah yang mewadahi aktivitas liturgi, maka pembahasan menggunakan kajian semiotika untuk membaca tanda dan makna pada bentuk arsitektur agar dapat menjaga ekspresi sakralnya.

Metodologi penelitian yang digunakan adalah metode kualitatif dengan menggunakan prinsip semiotika Peirce dan penerapannya pada arsitektur Gereja. Prinsip tersebut kemudian digunakan untuk menganalisis kedua kasus studi pada setiap lingkup perancangan. Lingkup perancangan meliputi: (1) Lingkup lingkungan sekitar; (2) Lingkup tapak; (3) Lingkup bentuk. Analisis ini menggunakan prinsip semiotika yang di elaborasi dengan prinsip Gereja Katolik untuk menghasilkan pedoman perancangan arsitektur Gereja Katolik.

Tujuan penelitian adalah untuk menemukan ekspresi sakral yang lebih dominan antara Gereja Santo Petrus dan Gereja Santa Maria Tujuh Kedukaan dari simbol-simbol yang melekat pada elemen arsitektur Gereja Katolik.

Hasil penelitian menunjukkan bahwa ekspresi sakral terdapat pada (1) Lingkup lingkungan sekitar; (2) Lingkup tapak; (3) Lingkup bentuk Gereja Santo Petrus lebih dominan dibandingkan Gereja Santa Perawan Maria Tujuh Kedukaan.
\end{abstract}

Kata kunci: Semiotika peirce, ekspresi sakral, gereja katolik

\begin{abstract}
Title: Architectural Design Symbolism Catholic Church of Saint Peter and The Virgin Mary Catholic Church Santa Grief Seven in Bandung

As a place of holy worship, a Catholic Church should posses a sacred interior and exterior expression. Modernization has caused a good deal of this sacred expression of the Catholic Church to fade. As Catholic Church is a place of worship that supports all liturgical activities, semiotic theory are used to analyze and decipher its architecture to preserve sacredness.

The research methodology that was employed was qualitative methods using Peirce's semiotic principles and their implementation in Church architecture. The principle was then used to analyze two case studies in every detail of their draw up. The area of planning encompassed: (1) Scope of the surrounding environment; (2) Scope of the site; (3) Scope of the form. This analysis employed semiotic principles that were elaborated with Catholic Church principles to create a guideline in the architectural planning of a Catholic Church.

The purpose of this research is to find the most dominant sacral expression between Santo Petrus Church and the Santa Perawan Maria Tujuh Kedukaan Church by means of the symbols attached to the architectural elements between these two Catholic Churches.
\end{abstract}


The results of this study were that sacral expression in terms of (1) Scope of the surrounding environment; (2) Scope of the site; (3) Scope of the form are more dominant in the Santo Petrus Church compared to the Santa Perawan Maria Tujuh Kedukaan Church.

Keywords: Peirce's semiotics, sacral expression, catholic church

\section{Pendahuluan}

Fungsi bangunan yang sama dapat saja mempunyai bentuk arsitektur yang jauh berbeda. Demikian juga halnya dengan bentuk bangunan yang relatif sama dapat memiliki fungsi yang jauh berbeda (Trisno, 2015).

Arsitektur Gereja Katolik berkembang dengan sangat beragam seperti "composed of cement cubes, glass boxes, crazy shapes and confuses space". Perkembangan yang sangat beragam ini menyebabkan Paus Benediktus XVI menjadi khawatir terjadi pemudaran ekspresi sakral pada bentuk arsitektur Gereja Katolik (Vatican Insider, 2011), karena menurut liturgi katolik, ekspresi sakral seharusnya terpancar pada bentuk bangunannya.

Arsitektur Gereja Katolik harus mampu membawa umat pada keyakinan bahwa mereka memasuki sebuah tempat yang istimewa, yang menyadarkan orang bahwa pada kenyataannya mereka memasuki area sakral, tempat Tuhan tinggal, bukan memasuki rumah tinggal biasa. melainkan ruang yang memiliki nilai kosmologi berupa titik orientasi dan berkaitan dengan pengalaman religius, mengandung nilai spiritual, kesucian, dan ritual (McGuire, 2015). Arsitektur Gereja merupakan ruang atau tempat liturgis (Suryanugraha, 2004), karena pada setiap perayaan liturgi selalu menggunakan simbol-simbol. Perayaan liturgi sebagai karya keselamatan Allah berlangsung dalam bentuk simbol atau tanda karena Allah menjumpai manusia dalam bentuk simbol atau tanda. Manusia adalah mahkluk simbolis, maka perayaan liturgi sungguh berciri simbolis karena dilaksanakan oleh manusia (Martasudjita, 2011).

Mengingat Gereja katolik sarat akan simbol, maka ilmu semiotika dan ilmu perancangan arsitetur sebagai alat interpretasinya. Penelitian ini dilakukan pada dua bangunan Gereja Katolik tertua di kota Bandung, yaitu Gereja Santo Petrus dan Gereja Santa Perawan Maria Tujuh Kedukaan. Langkah pertama penelitian adalah mendata elemen arsitekturnya secara rinci. Langkah kedua teori semiotika Peirce (Cobley, 2002) dielaborasi dengan teori prinsip perancangan arsitektur (Salura, 2010), digunakan untuk membaca tanda yang paling dominan pada elemen arsitektur kedua Gereja Katolik. Langkah ketiga adalah mengungkap ekspresi sakral pada tanda dominan yang ada.

Penelitian ini merupakan penelitian yang penting dan tergolong langka dalam kajian arsitektur Gereja Katolik karena kajian arsitektur Gereja masih langka yang menggunakan pendekatan gabungan antara teori semiotika Peirce dan teori perancangan arsitektur Salura. Tujuan penelitian ini adalah mengungkap seluruh hubungan yang terjalin antara kegiatan liturgi dengan ekspresi sakral arsitektur Gereja Katolik. 
Manfaat yang didapat pada penelitian ini adalah pertama, memahami seluruh hubungan antara kegiatan liturgi dengan ekspresi sakral. Kedua, mengidentifikasi elemen-elemen arsitektur apa saja yang dapat menciptakan ekspresi sakral. Ketiga, memosisikan kajian ekspresi sakral arsitektur gereja ke dalam konteks perubahan global.

\section{Metodologi}

Penelitian ini menggunakan metode kualitatif dengan cara memahami fenomena Gereja Katolik yang diduga kehilangan bentuk dan ekspresi sakral sebagai tempat ibadah. Penelitian dimulai dengan studi literatur tentang arsitektur Gereja katolik, ilmu semiotika
Peirce (Cobley, 2002) dan prinsip perancangan arsitektur (Salura, 2015).

Penelitian dilanjutkan dengan pengumpulan data yang dilakukan dengan dua cara, yaitu : (1)Perekaman visual bangunan, interior dan tapak lingkungan Gereja; (2)Pengamatan pada aktivitas kegiatan Gereja. Perolehan data dianalisis berdasarkan teori semiotika dan teori dimensi arsitektural (bagan 1). Kerangka konseptual ini menjelaskan simbolisasi ekspresi sakral Gereja dicari menggunakan teori dimensi arsitektur yang penekanannnya pada fisik aspek bangunan dan semiotika Peirce. Tanda indeks, ikon, dan simbol akan di cari pada arsitektur Gereja Katolik yang lebih dominan dalam lingkup lingkungan sekitar, lingkup tapak, dan lingkup bentuk dari kedua obyek studi.

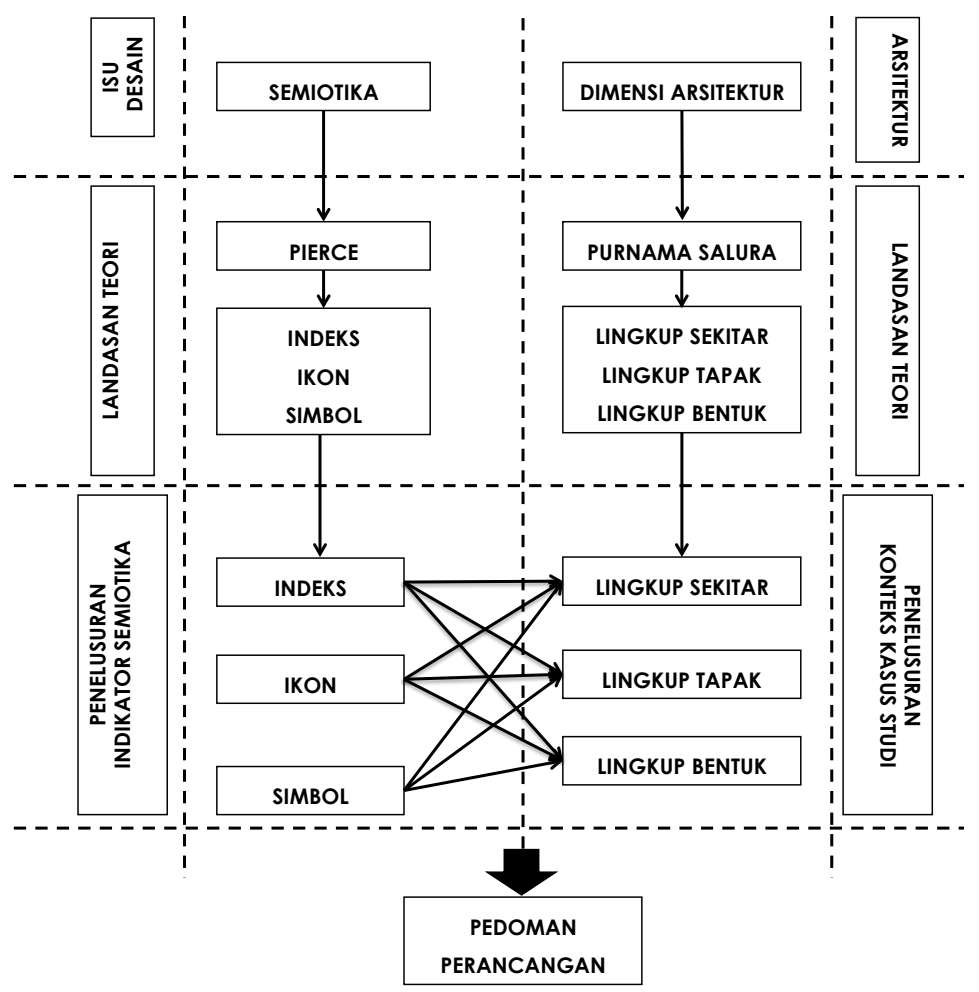

Gambar 1. Kerangka konseptual penelitian

Sumber: Hasil Analisis, 2016 


\section{Kasus Studi}

Kasus studi yang dipilih adalah Gereja tertua di kota Bandung. Hingga saat ini kedua Gereja tersebut masih dalam keadaaan asli seperti pada waktu diciptakan. yaitu: (1) Gereja Katolik Santo Petrus (Gereja Katedral), dibangun tahun 1903 oleh arsitek C.P.Wolff Schoemaker, Jl. Merdeka no. 14; (2) Gereja Santa Perawan Maria 7 (tujuh) Kedukaan (Gereja Pandu), dibangun tahun 1935 oleh arsitek Fermont Cuypers, J1. Pandu no.4.

\section{Analisa dan Hasil}

Analisis dari lingkup perancangan ini meliputi: (4.1) Lingkup lingkungan sekitar; (4.2) Lingkup tapak; (4.3) Lingkup bentuk.

\section{Lingkup Lingkungan Sekitar}

Analisis pada lingkup lingkungan sekitar adalah membandingan antara pola tapak dengan pola yang ada pada lingkungan sekitar tapak. Analisis ini meliputi dua aspek, yaitu: (a) pola bangunan dan tapak sekitar; (b) dimensi bangunan.

a. Pola Bangunan dan Tapak Sekitar

Pola bangunan dan tapak sekitar Gereja Santo Petrus (obyek 1) berbentuk persegi dan berada di sudut jalan. Penempatan pintu masuk dipilih dari jalan sekunder (jalan Aceh) untuk mengurangi kemacetan pada jalan utama (jalan Merdeka). Pola bangunan dan tapak sekitar Gereja Santa Perawan Maria Tujuh Kedukaan (obyek 2) berbentuk elips yang meruncing pada kedua ujungnya, sehingga pada penempatan pintu masuk terdapat di sisi yang memanjang, pada sisi memanjang di pilih arah sirkulasi kendaraan dari dalam kota (tabel 1). Obyek 1 dan 2 memiliki tanda simbol $^{1}$ karena berada pada persimpangan jalan dan dikelilingi jalan. Pola bentuk tapak yang berada di tengah dan dikelilingi jalan akan sangat menunjang ekspresi sakral, pola bentuk tapak yang berada pada persimpangan dengan air manjur sebagai node jalan juga dapat menunjang ekspresi sakral (Salura, 2015).
1 Simbol adalah suatu kesepakatan atau 


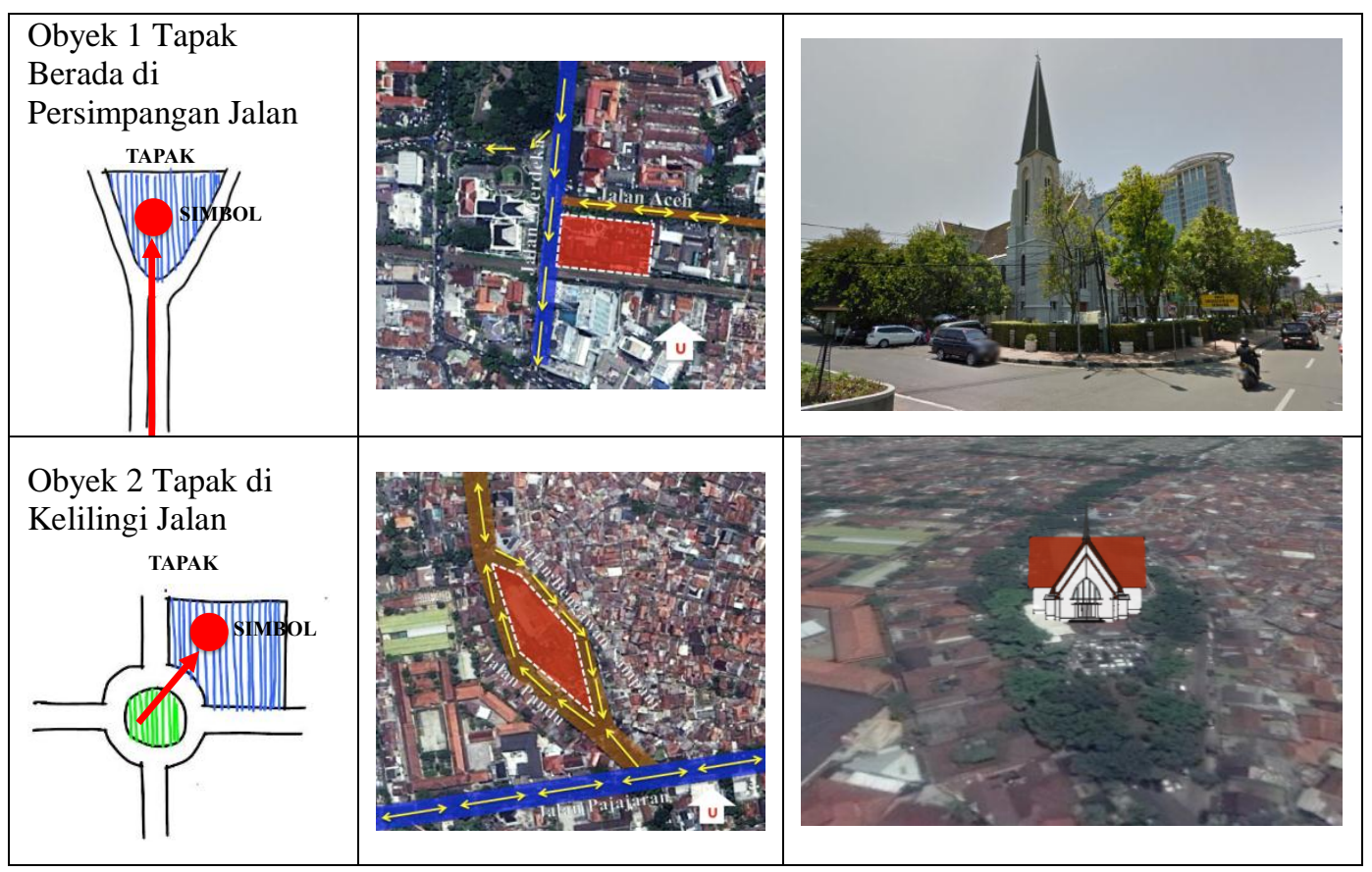

Tabel 1. Pola bangunan dan tapak sekitar Sumber: Hasil Analisis, 2016

Obyek 1 terletak di sudut jalan, sehingga memiliki dua sisi wajah, yaitu pada jalan utama dan jalan sekunder. Menara lonceng sebagai elemen liturgis Gereja terletak pada sudut bangunan. Bentuknya yang menjulang tinggi dan runcing membuat Gereja menjadi simbol

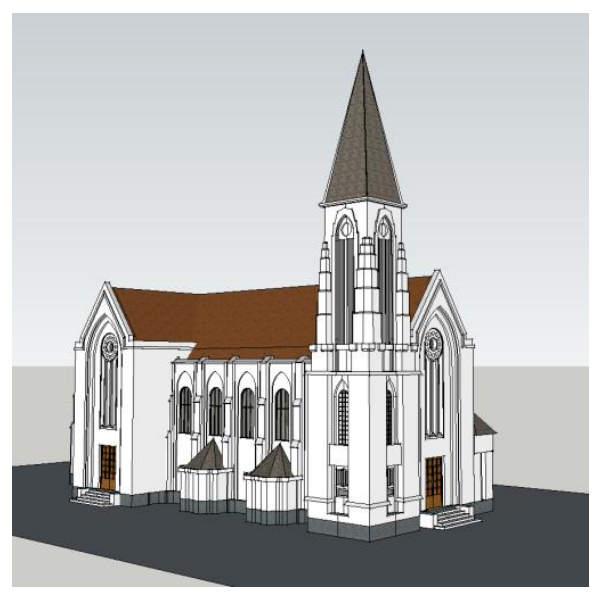

pada lingkungannya dengan komposisi mengarah ke atas atau sakral. Tanpa atap menara lonceng yang berbentuk runcing menunjuk ke atas, Gereja kehilangan identitas sakralnya (gambar 1).

Gambar 1. Obyek 1 menara lonceng gereja dengan atap (kiri), dan tanpa atap (kanan) Sumber: Hasil Analisis, 2016 
Obyek 2, bangunan terletak di aksis dan dikelilingi oleh jalan, sehingga bangunan memiliki 4 sisi wajah. Posisi menara lonceng pada obyek 2 terletak ditengah bangunan agar dapat terlihat dari 4 arah. Gereja menjadi simbol pada tapaknya, tanpa menara lonceng bangunan akan menjadi indeks ${ }^{2}$ pada lingkungannya karena serupa dengan bangunan sekertariat pada tapak (gambar 2).
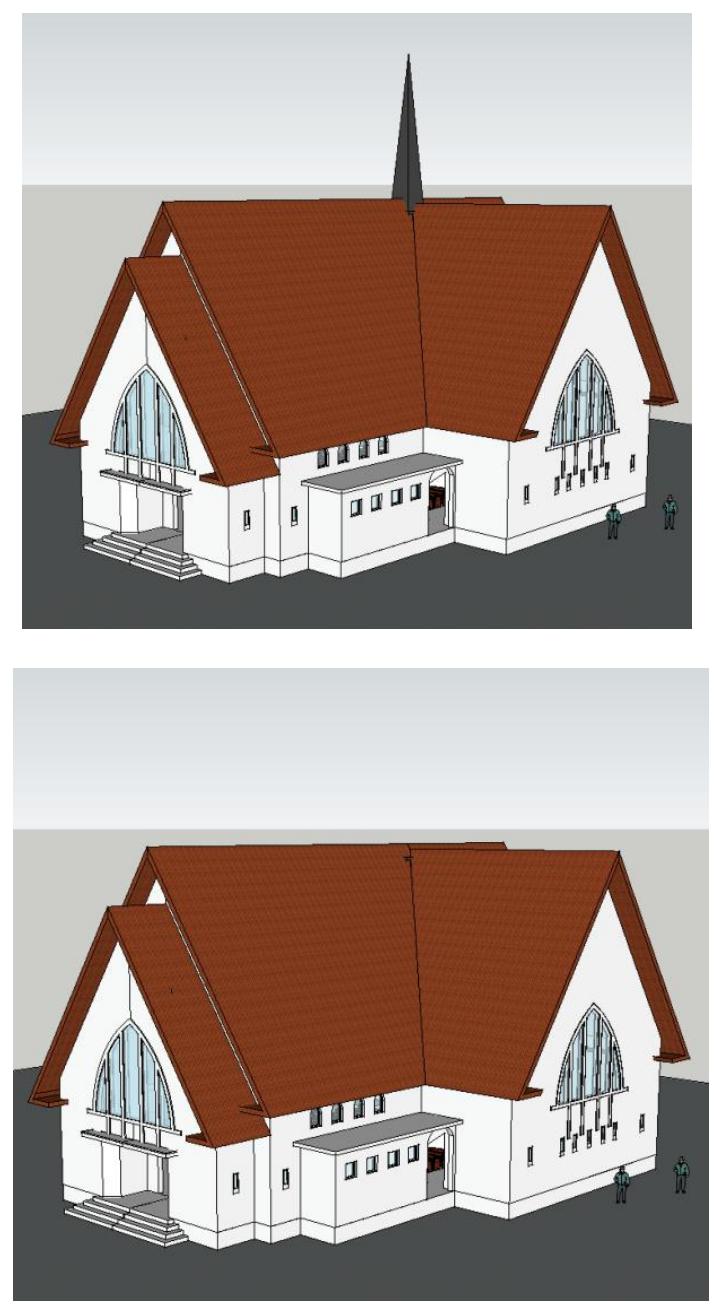

Gambar 2. Obyek 2 dengan menara lonceng (atas), tanpa menara lonceng (tengah) Sumber: Hasil Analisis, 2016

\footnotetext{
${ }^{2}$ Indeks adalah sesuatu yang memiliki hubungan menyatu (sebab-akibat) antara penanda dan petanda.
}

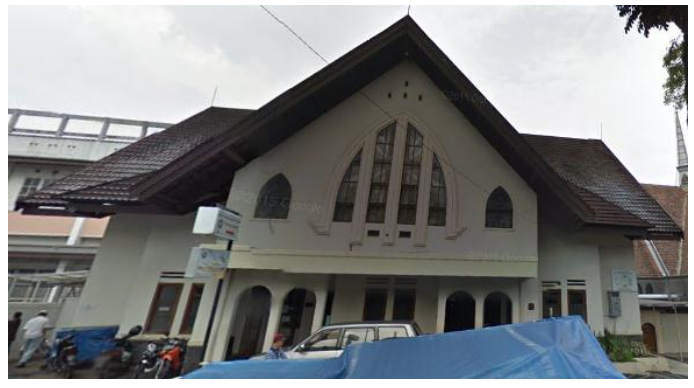

Gambar 3. Bangunan sekertariat (obyek 2)

Sumber: Dokumentasi Penulis, 2016

b. Dimensi Bangunan

Dimensi bangunan obyek 1 memiliki kesamaan dengan dimensi bangunan Bank Indonesia (sisi barat) dan Hotel Grand Royal Panghegar (sisi selatan). Bangunan Bank Indonesia dan Hotel Grand Royal Panghegar memiliki ketinggian yang sama dengan obyek 1 (gambar 4), tetapi dengan adanya menara lonceng pada obyek 1 menguatkan karakter bangunan sehingga dapat menjadi simbol dan mencolok pada lingkungannya. Skyline Lingkungan sekitar obyek 1 memperlihatkan atap menara lonceng yang tinggi dan meruncing menjadi bagian yang menonjol pada lingkungannya. 


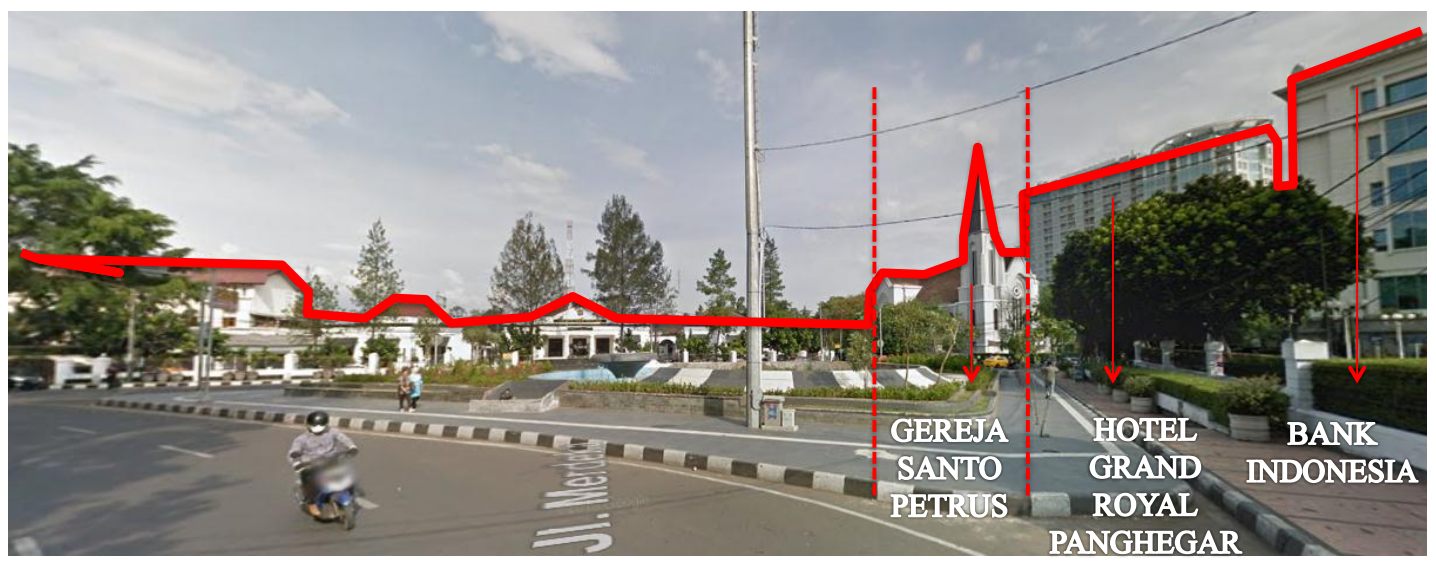

Gambar 4. Dimensi dan skyline obyek 1

Sumber: Hasil Analisis, 2016

Dimensi bangunan dan tapak obyek 2 terhadap lingkungan sekitarnya memiliki kesamaan dan karakter yang serupa,

sehingga obyek 2 menjadi tanda indeks karena tidak menonjol pada lingkungan sekitarnya (gambar 5).

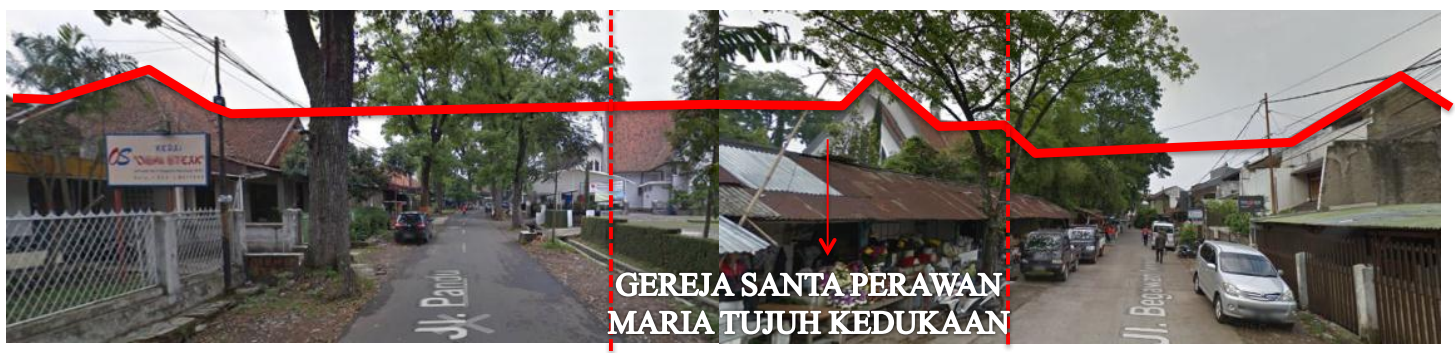

Gambar 5. Dimensi dan skyline obyek 2

Sumber: Hasil Analisis, 2016

\section{Lingkup Tapak}

Analisis pada lingkup tapak adalah relasi antara masa bangunan Gereja, berikut masa bangunan penunjang lainnya (jika ada) dengan ruang terbuka dalam tapak. Relasi ini penting karena dapat menentukan apakah masa bangunan Gereja dapat berdiri menonjol di dalam tapak atau justru malah tersisih oleh masa bangunan lain. Demikian juga apakah ruang terbuka di dalam tapak menunjang ekspresi masa Bangunan Gereja.

Ruang terbuka pada tapak obyek 1 dan 2 memiliki tanda simbol karena berada di depan dan samping bangunan (gambar 6). Ruang terbuka yang berada dimuka masa bangunan berpotensi menciptakan ekspresi monumental sakral (Salura, 2015). 

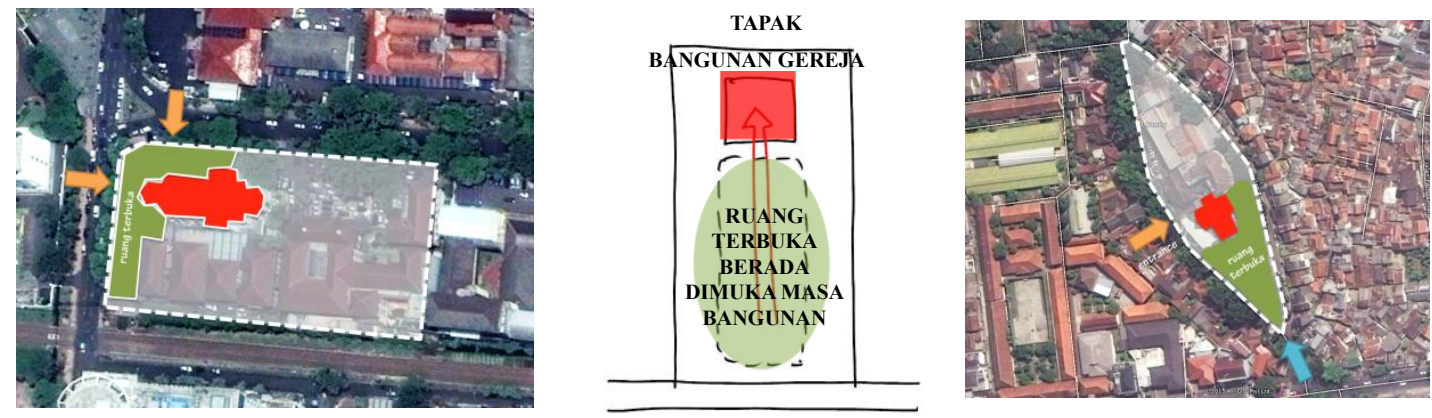

Gambar 6. Posisi ruang terbuka pada obyek 1 (kiri) dan obyek 2 (kanan)

Sumber: Hasil Analisis, 2016

Obyek 1 dalam tata kota berada dalam kawasan pertahanan dan keamanan dengan peraturan bangunan dengan GSB $1 / 2 \times$ lebar rumija (ruang milik jalan). Rumija Obyek 1 adalah 13 meter, maka GSB Obyek 1 pada sisi utara (Jalan Aceh/sekunder) adalah 6 meter dan sisi timur (Jalan Merdeka/utama) adalah 6,5 meter. Offset bangunan obyek 1 adalah
10,5 meter pada sisi utara dan 6 meter pada sisi barat. Obyek 1 menjadi tanda indeks karena ekspresi monumental sakral tidak dapat tercipta karena jarak pengamat kurang dari 51 meter, sehingga bangunan tidak dapat terlihat secara utuh di dalam tapaknya (gambar $7)$.

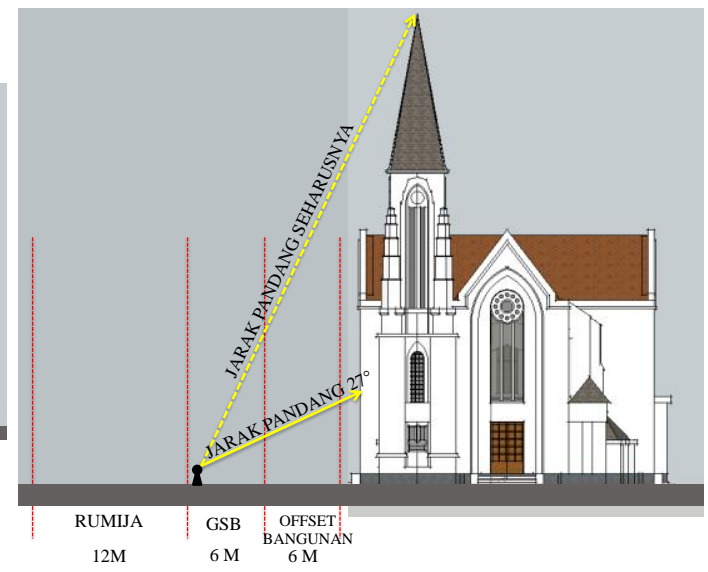

Gambar 7. GSB dan jarak obyek 1 pada sisi Utara (kiri) dan sisi Barat (kanan)

Sumber: Hasil Analisis, 2016

Obyek 2 dalam tata kota berada di kawasan perumahan berkepadatan tinggi dengan peraturan bangunan dengan GSB $1 / 2$ x lebar rumija, untuk kapling kurang dari $60 \mathrm{~m}^{2}$ GSB sekurang-kurangnya 2 meter. Rumija obyek 2 adalah 9 meter, maka GSB obyek 2 adalah 4,5 meter untuk sisi barat daya (Jalan Pandu) dan sisi timur laut (Jalan Bengawan Sampani). Offset bangunan pada obyek 2 adalah 67,5 meter dan cukup untuk membuat Gereja menjadi tanda simbol karena ekspresi monumental sakral pada tapaknya, karena jarak pandang minimal yang dibutuhkan pengamat untuk melihat Gereja secara utuh adalah 29,5 
meter. Namun walaupun offset sudah mendukung, Gereja menjadi tanda indeks, karena tidak terlihat monumental sakral. Hal ini disebabkan faktor vegetasi yang rimbun, tumbuhnya fungsi

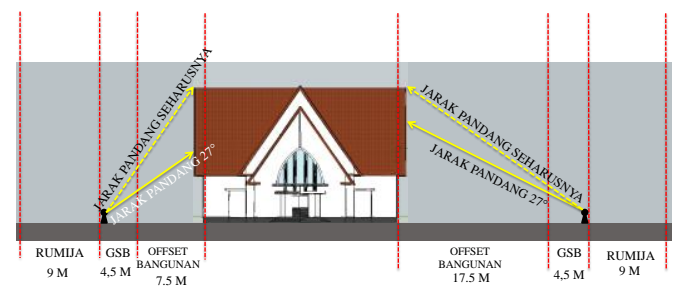

bangunan diluar tapak yang menutupi bangunan Gereja, dan bentuk Gereja yang serupa dengan bangunan sekitarnya (gambar 8).

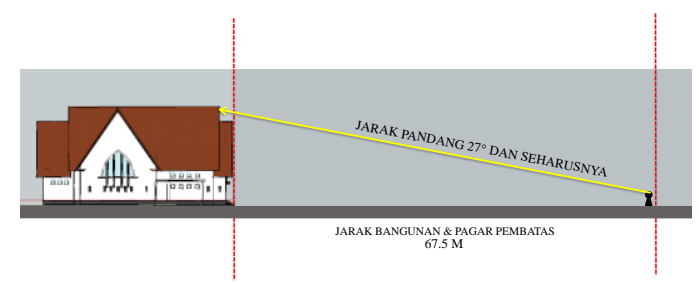

Gambar 8. GSB dan jarak obyek 2 pada sisi Barat Laut (kiri) dan sisi Timur Laut (kanan) Sumber: Hasil Analisis, 2016

Umat katolik pada zamannya terkandung "rumah asli manusia" (man's membangun Gereja katolik menghadap original home) dan menurut Santo arah matahari terbit (timur), artinya Thomas Aquinas (1225-1274), Yesus bagian depan dan pintu masuk utama sebagai Tuhan akan datang dari Timur terdapat di barat; sebab yang ditekankan adalah orientasi doa pemimpin agama. Arah timur dipercaya memiliki ragam makna simbolis yakni menurut tradisi Yahudi timur arah hadap ke kota Yerusalem (the sacred city) ; menurut bangsa Roma, arah timur menghadap kepada dewa matahari ; menurut teologis Katolik, Santo Gregorius dari Nyssa (335-395M) mengatakan, arah timur untuk menghakimi umat manusia. (Srisadono, 2013). Obyek 1 memiliki tanda simbol karena arah hadap bangunan dalam tapak mengikuti orientasi timur-barat, sedangkan obyek 2 memiliki tanda indeks karena orientasi arah hadap bangunan dalam tapak menghadap ke barat laut-tenggara (gambar 9).
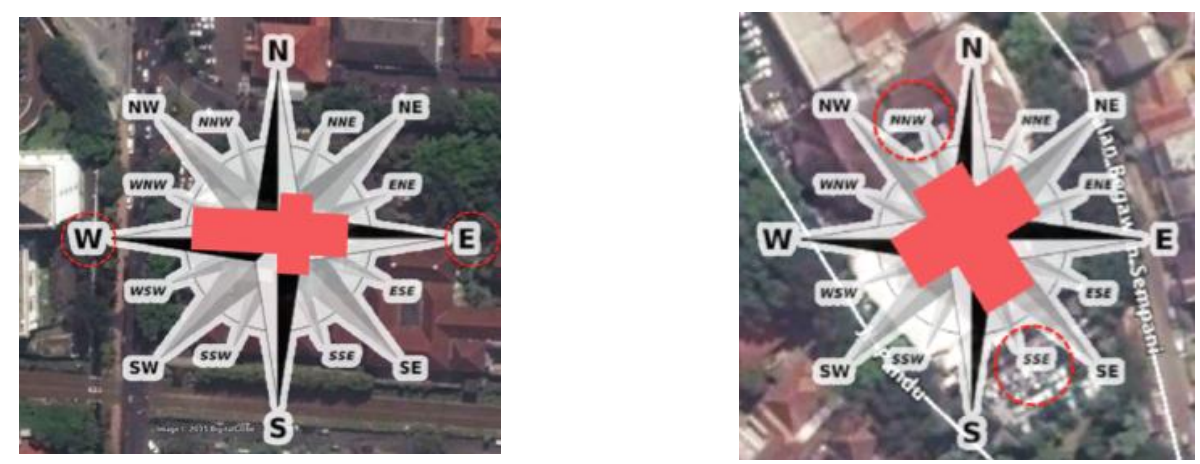

Gambar 9. Orientasi bangunan dan letak pintu masuk pada obyek 1 (kiri) dan obyek 2 (kanan)

Sumber: Hasil Analisis, 2016 


\section{Lingkup Bentuk}

Analisis yang akan dilakukan pada lingkup bentuk adalah (a) relasi antara pelingkup bangunan dengan ruang kegiatan dalam bangunan, bagaimana pelingkup ini dapat berdiri, struktur dan konstruksi elemen bangunannya. Apakah struktur kolom penunjang berada ditengah ruang sehingga menghalangi gerak ruang kegiatan atau sejalan dengan gerak ruang kegiatan (gambar 10); (b) relasi antara kualitas batas atau sosok kulit bangunan dengan persyaratan kegiatan di dalam bangunan, apakah derajat keterbukaan atau ketertutupan elemen sosok sebagai pembatas yang ada sejalan dengan persyaratan kegiatan liturgi, atau berlawanan dan tidak berhubungan dengan persyaratan kegiatan liturgi (gambar 11).

Hasil analisis adalah apakah aspek-aspek lingkup bentuk sebagai tanda indeks, ikon atau simbol. Indikator yang menunjang ekspresi sakral adalah apabila aspek-aspek pada lingkup bentuk bangunan Gereja dengan gerak kegiatan yang ada, berada pada rentang tanda simbol liturgi atau ikon yang menuju simbol liturgi.

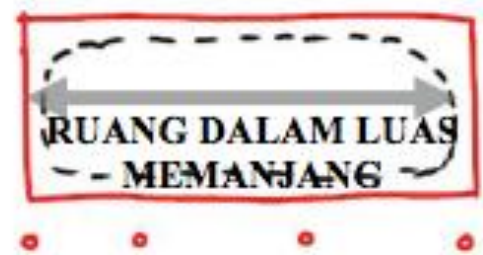

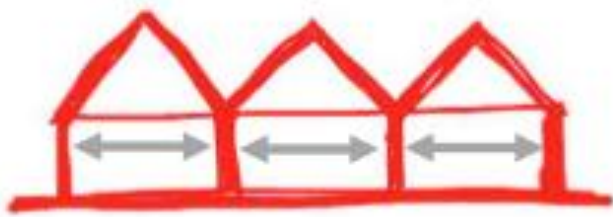

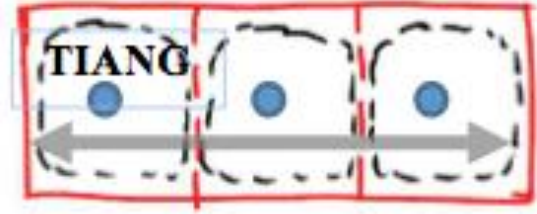

Gambar 10. Keterkaitan bentuk-struktur-konstruksi dengan ruang dalam Sumber: LPPM Gereja Lanjut
HUBUNGAN RUANG LUAR DAN DALAM PADA OBYEK STUDI

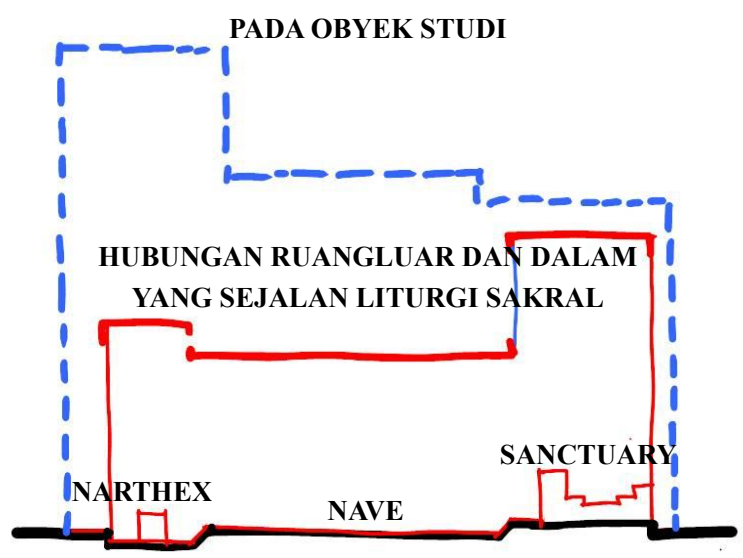

Gambar 11. Keterkaitan elemen pembatas dan rangkuman hubungan ruang dalam-luar Sumber: LPPM Gereja Lanjutan 
Bentuk denah obyek 1 dan obyek 2 adalah salib latin. Bentuk denah salib merupakan kepercayaan tradisi kuno di Eropa pada zaman kegelapan ketika Gereja masih diselimuti takhayul. Menggambar salib di atas tanah dipercayai melindungi orang atau
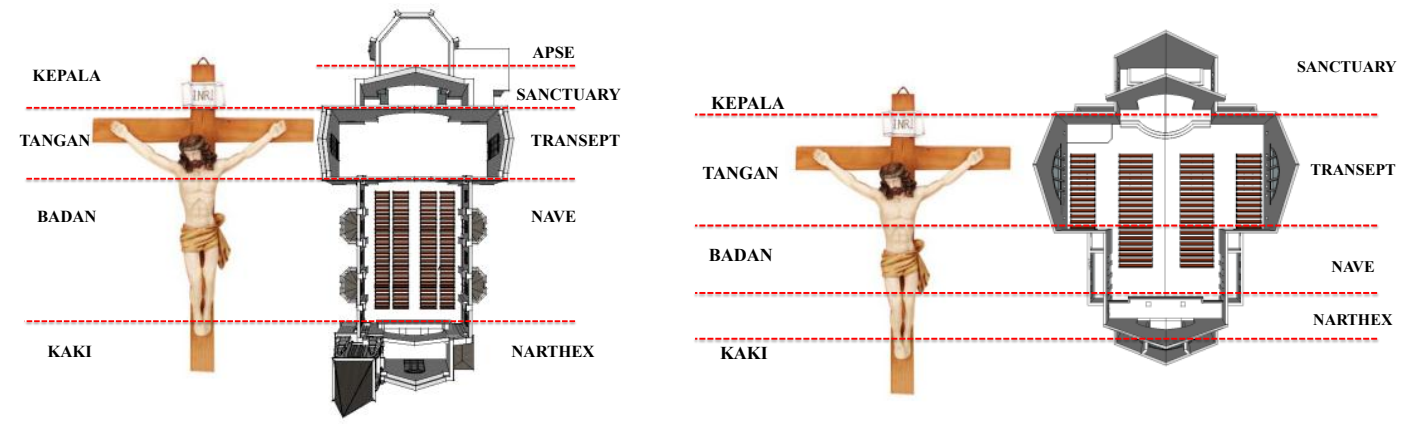

Gambar 12. Perbandingan salib Latin dan denah obyek 1 (kiri) dan obyek 2 (kanan) Sumber: Gambar Salib-Google Image

Kedua obyek studi memiliki tanda simbol karena ekspresi masa bangunan Gereja dengan ruang gerak dalam yang sejalan (gambar 12). Ruang linear yang luas terbentuk dari area panti umat (nave) menuju panti imam (sanctuary) tanpa struktur kolom penghalang memberikan efektifitas dan efisiensi ruang yang luas membuat ekspresi sakral dari liturgi dapat terpenuhi (Salura, 2015).

Elemen pembatas antara ruang luar dan dalam pada kedua kasus studi terdiri dari dinding dan atap. Dinding pada Gereja merupakan elemen pembatas utama yang berpengaruh pada kegiatan liturgi. Dinding Gereja memiliki bukaan jendela dan pintu.

Pada Obyek 1 dan 2 memiliki elemen jendela dengan modul yang beragam terletak atas kepala manusia. Hal ini memperlihatkan bahwa kedua Gereja dengan sengaja memisahkan ruang luar dan ruang dalam agar liturgi dapat berjalan tanpa ada gangguan dari luar. bangunan yang berdiri di atas salib itu dari gangguan setan (Winarwan, 2002). Tanda dominan pada kedua obyek adalah simbol, karena bentuk denah memilik makna simbolik sesuai teologi katolik (gambar 12). 


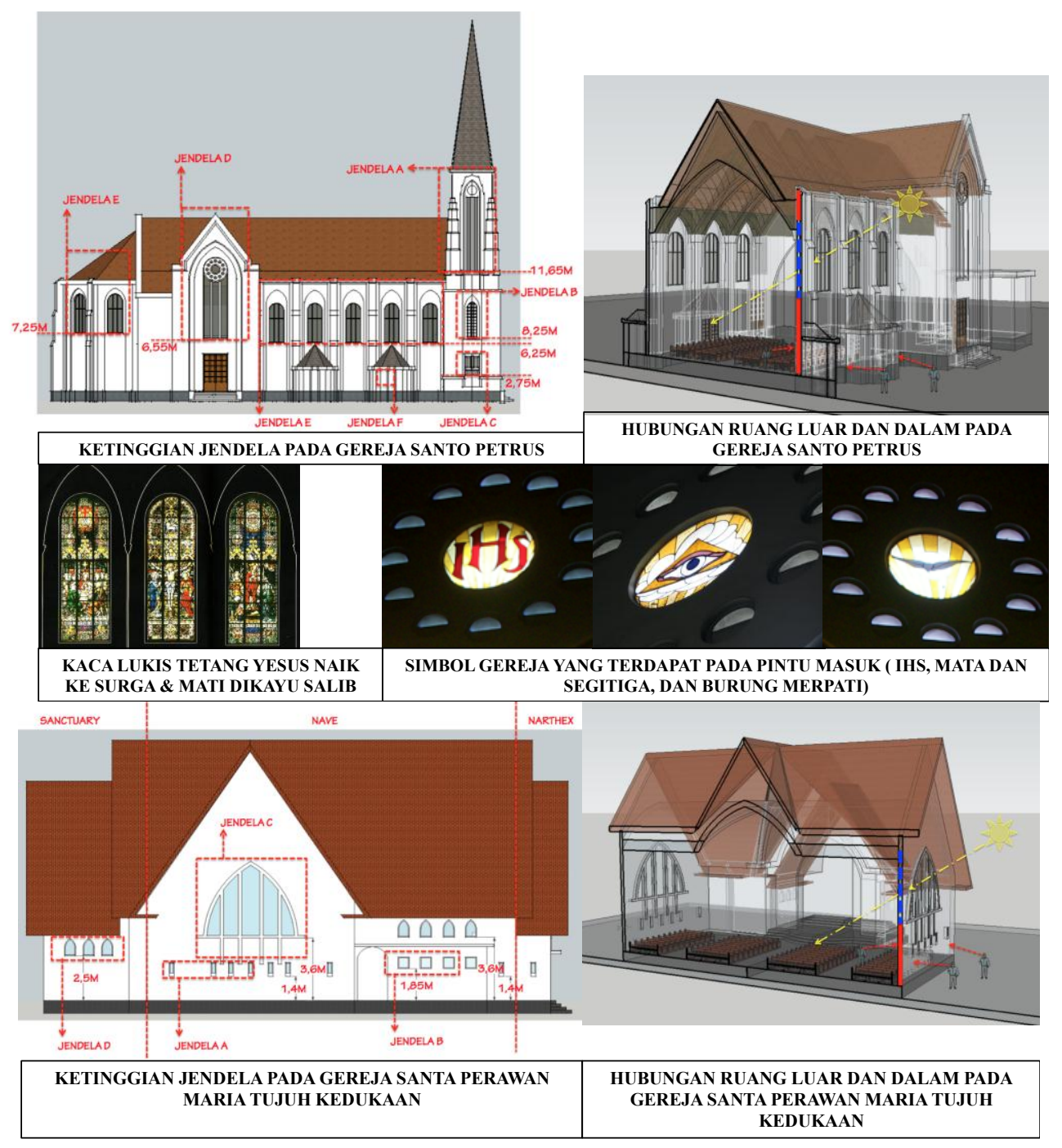

Gambar 13. Letak sosok pembatas dan hubungan ruang luar dan dalam pada obyek 1 (atas) dan 2 (bawah)

Sumber: Hasil Analisis, 2016

Elemen pintu pada kedua kasus studi menggunakan material kayu solid dengan motif ornamen yang geometris. Pada obyek 1 elemen pintu memiliki tanda simbol, karena kesannya yang formal dan kokoh, seperti pada pintupintu kerajaan. Umat kristiani percaya

bahwa Gereja adalah rumah Allah, kerajaan Allah. Sedangkan pada obyek 2 elemen pintu terlihat sederhana seperti pada rumah tinggal, sehingga tidak menciptakan kesan ekspresi sakral (gambar 14). 

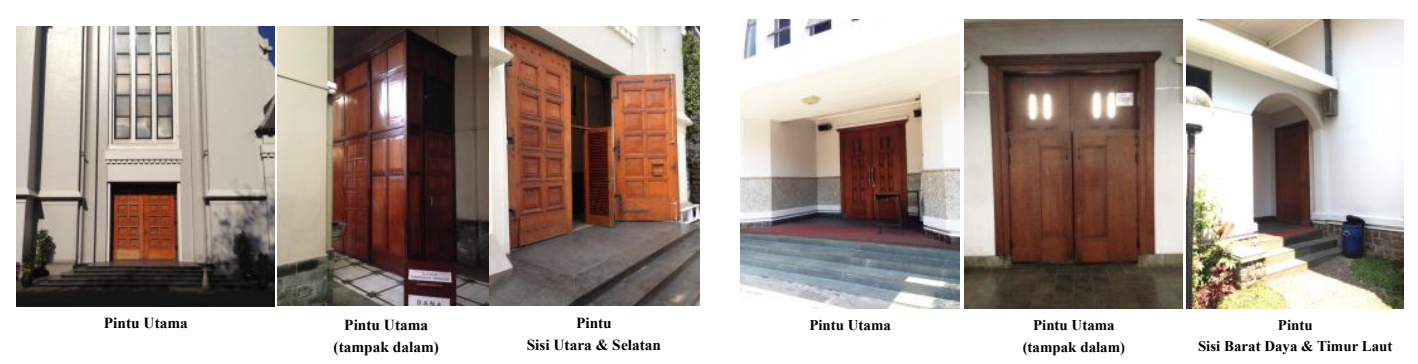

Gambar 14. Elemen sosok pembatas (pintu) pada kedua obyek studi

Sumber: Dokumentasi Penulis, 2016

Hubungan bentuk ruang luar dan ruang dalam yang sejalan dengan liturgi katolik adalah ketika ruang luar dan dalam memiliki urutan sakral (narthexnave-sanctuary) yang terlihat dari ruang dalam ke bentuk luar obyek bangunan. Semakin sakral ruang, maka semakin tinggi alas dan penutup ruang tersebut. (Salura, 2015). Obyek 1 dan 2 menjadi indeks karena tidak sejalan dengan liturgi sakral. Area panti imam pada
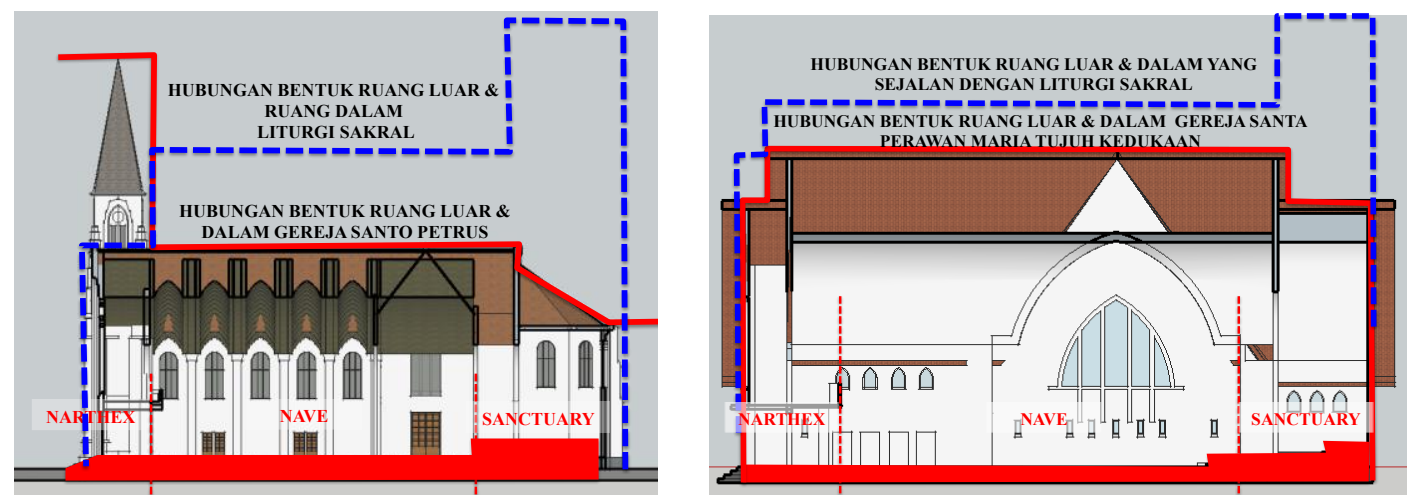

Gambar 15. Hubungan bentuk ruang luar dan dalam yang sejalan dengan liturgi sakral pada obyek 1 (kiri) dan obyek 2 (kanan)

Sumber: Hasil Analisis, 2016

\section{Kesimpulan}

Berdasarkan analisis kedua obyek studi, maka ditemukan, obyek 1 (Gereja Santo Petrus) memiliki ekspresi sakral yang lebih dominan dibandingkan obyek 2 (Gereja Santa Perawan Maria Tujuh obyek 1 seharusnya memiliki plafond yang paling tinggi, tetapi pada obyek 1 justru memilik plafond yang paling rendah. Sedangkan pada obyek 2 area serambi dan panti imam memiliki ketinggian plafond yang sama; plafond yang tertinggi pada bangunan berada di area panti umat yang memiliki urutan sakral ke dua (gambar 15).
Kedukaan). Pada obyek 1 ditemukan simbol-simbol Gereja yang melekat pada jendela sehingga suasana sakral pada obyek 1 lebih terbentuk dan terasa. 


\section{Daftar Pustaka}

Triyosoputri, E. (1992). Evaluasi Purna Pakai Alun-alun Malang dengan Pengekatan Aspek Fungsional. Tesis Magister Arsitektur, Institut Teknologi Bandung.

Cobley, P., dan Jansz, L. (2002). Mengenal Semiotika For Beginners. Mizan, Bandung.

La Stampa. (2011). New Vatican Commission Crack Down on Church Architecture. Vatican Insider, Inquiries and Interviews, Hal. 1 (online) diakses 18 Desember 2015.

http://www.lastampa.it/2011/11/21/ vaticaninsider/eng/inquiries-andinterviews/new-vativancommission-crack-down-on-churcharchitectureJ6JHAcO10EfabUXmtg7VWK/pagi na.html.

Martasudjita, E. Pr. (2011). Liturgi: Pengantar untuk Studi dan Praksis Liturgi. Kanisius, Yogyakarta.

McGuire, D. (n.d). Church Architecture and Sacred Space. TheologyUniversity of Great Falls. (online) diakses 16 April 2015

Salura, P. (2015). Sebuah Kritik: Arsitektur yang Membodohkan. Gakushudo Publisher, Jakarta.

Srisadono, Y. D. (2013). Konsep Ruang Sakral Gereja Katolik dan Perwujutadnya Dalam Inkulturasi Arsitektur Gereja Katolik Bali. Tesis. Universitas Katolik Parahyangan, Bandung. 